\title{
SÉCULO XXI - UMA PERSPECTIVA CRÍTICA CRISE FINANCEIRA GLOBAL E O CAPITALISMO DO
}

Francisco Luiz Corsi ${ }^{\mathrm{i}}$

UNESP-Marilia

flcorsi@uol.com.br

Giovanni Alves ${ }^{\mathrm{ii}}$

UNESP-Marilia

giovanni.alves@uol.com.br

\section{RESUMO:}

O texto se propõe a apresentar os traços marcantes da conjuntura de crise financeira global de 2008, salientando que o desabamento dos mercados financeiros explicitou a natureza contraditória do sistema mundial do capital sob a predominância da financeirização da riqueza capitalista. A novidade da nova crise global não está no estouro da bolha especulativa em 2008, mas sim, sua intensidade e a dimensão do cataclismo financeiro global, principalmente em suas repercussões não apenas no plano da economia, mas da política, geopolítica e da luta de classes nos próximos anos. Defendemos a hipótese que a nova dimensão do capitalismo global irá significar, por um lado, (1) o acirramento das lutas politicas e sindicais das massas assalariadas contra o Estado político do capital e (2) o aprofundamento das tendências destrutivas do sistema mundial do capital no âmbito produtivo.

Palavras-chave: Capitalismo, crise global, economia política, trabalho, reestruturação produtiva

\section{GLOBAL FINANCIAL CRISIS OF CAPITALISM XXI CENTURY - A CRITICAL PERSPECTIVE}

\begin{abstract}
:
Our objective is to present the main traces of the conjuncture of global financial crisis of 2008, pointing out that the landslide of the financial markets demonstrated the contradictory nature of the world-wide system of the capital under the predominance of the financeirization of the capitalist wealth. The newness of the new global crisis is not in the burst of the speculative bubble in 2008, but yes, its intensity and the dimension of global the financial cataclysm, mainly in its repercussions not only in the plan of the economy, but of the politics, geopolitics and of the fight of class in the next years. We defend the hypothesis that the new dimension of the global capitalism will go to mean, on the other hand, (1) the increase of the fights syndical politics and of the wage-earning masses against the State politician of the capital and (2) the deepening of the destructive trends of the world-wide system of the capital in the productive scope.
\end{abstract}

Key-words: Capitalism, global crisis, economy politics, work, productive reorganization

\section{À guisa de Introdução}

Nosso objetivo é apresentar os traços marcantes da crise financeira global de 2008. Como a crônica de uma morte anunciada, o desabamento dos mercados financeiros explicitou a natureza contraditória do sistema mundial do capital sob a predominância da 
financeirização da riqueza capitalista. A novidade não está no estouro da bolha especulativa em 2008, mas sim, sua intensidade e a dimensão do cataclismo financeiro global, principalmente em suas repercussões não apenas no plano da economia, mas da política, geopolítica e da luta de classes nos próximos anos.

Defendemos a hipótese que a nova dimensão do capitalismo global irá significar, por um lado, (1) o acirramento das lutas politicas e sindicais das massas assalariadas contra o Estado politico do capital e (2) o aprofundamento das tendências destrutivas do sistema mundial do capital no âmbito produtivo.

Nessas condições de reorganização capitalista, deve emergir uma nova onda reestruturativa do capital sob as condições de uma economia capitalista recessiva. O ajuste das corporações industriais e a precarização do mercado de trabalho podem exacerbar traços de racionalização corporativa e manipulação sistêmica, além de ampliação da irracionalidade social (os elementos de barbárie social podem se agudizar, exigindo dos movimentos sociais novas formas de resistência estratégica).

É importante salientar que a crise do capitalismo global que emerge em 2008 é um dos momentos cruciais da crise estrutural do capital. Como a grande crise capitalista de meados de 1970, abre uma nova temporalidade histórico-social do capitalismo mundial. Aliás, a crise financeira global de 2008 é mais um dos elos da corrente critica da dinâmica capitalista sob a cris estrutural do capital. Desde meados da década de 1970 o sistema mundial do capital submergiu numa aguda instabilidade sistêmica vinculadas a natureza da financeirização da riquezaq capitalista como resposta estrutural à crise de superprodução. Naquele momento, a primeira recessão global do pós-guerra impulsionou uma nova fase de desenvolvimento capitalista que François Chesnais, por exemplo, chamou de "mundialização do capital".

Nos "trinta anos perversos", o capitalismo global emerge com alguns traços estruturais marcantes, caracterizado por uma pletora de reestruturações capitalistas nos vários campos da vida social. No bojo da nova arquitetura capitalista, gesta-se a predominância do capital financeiro que marcaria a dinâmica capitalista da décadas de 1980 a 2000, caracterizada pelas supremacia das politicas neoliberais, complexo de reestruturações produtivas e ampliação da financeirização da riqueza capitalista. Nesse contexto histórico, emerge um novo e precário mundo do trabalho e dissemina-se uma sócio-metabolismo da barbárie.

Na temporalidade histórica da crise estrutural do capital, a economia mundial tornase bastante instável, marcada por crises financeiras e estouros de bolhas especulativas, como a de 1987 e 1997. Em 2008, parece cumprir-se um ciclo ampliado de crises financeiras, com a crise atual assumindo uma dimensão inédita por conta do acumulo de contradições do regime de acumulação predominantemente financeirizado.

A crise financeira de 2008 atinge o "núcleo orgânico" do sistema mundial do capital, explicitando candentes determinações contraditórias postas no interior da economia capitalista do seu polo hegemônico (os Estados Unidos). Estados diante de uma crise financeira global que dissemina-se pelo capitalismo-mundo. Deste modo, a crise nasce no centro do sistema e sua intensidade e amplitude decorre da crise estrutural da valorização no amago do "núcleo orgânico".

Mas a idéia de crise estrutural do capital possui uma significação precisa - a exacerbação das contradições objetivas do modo de produção capitalista em suia dimensão planetária. O que implica na intensificação de formas fetichizadas (e estranhadas) da vida social. Crise estrutural, portanto, não se confunde estagnação (e queda) irremediável do capitalismo mundial. Pelo contrário, na ausência de uma subjetividade negadora do capital, o que os últimos "trinta anos perversos" demonstraram é que a crise estrutural significa a 
expansividade exacerbada da relação-capital. Deste modo, uma nova sociedade mundial emancipada não deve emergir da crise do capitalismo global, mas pelo contrário, deve-se exacerbar tendências destrutivas intensificadas pelas contradições sistêmicas

Ora, na medida em não se vislumbra no horizonte um sujeito histórico de classe capaz de "negação da negação" no âmbito global, o que se coloca é uma nova etapa de reprodução problemática do capitalismo mundial em sua etapa de barbárie social. Deve-se exacerbar as lutas das massas assalariadas no plano mundial, incluindo novos campos de valorização, como China, Índia e América Latina. Pode-se dizer que, nos interstícios nacionais, tendem a emergir novas experiencias anti-capitalistas que, a médio e longo prazo, podem colocar possibilidades de novo modo de produção da vida social. No bojo da processualidade histórica emergem elementos de uma nova sociabilidade pós-capitalista que alteram materialidade (e subjetividade) dos sujeitos históricos coletivos. Entretanto, estamos no âmbito da imanência da história e da contingencia da politica.

$\mathrm{Na}$ verdade, as crises financeiras no interior da crise estrutural - no plano da objetividade social e das reverberações nas instâncias produtivas - são momentos de reordenação interior do capital como "sujeito automático" de auto-valorização, momentos propiciadores de dinâmicas reestruturativas nos vários âmbitos da vida social.

Pode-se dizer que a década de 2010 deve significar um novo salto reestruturativo da vida social sob condições críticas de acumulação de valor. Crise, reestruturação $e$ expansividade da relação-capital (principalmente no campo sócio-territorial) - eis os registros sistêmicos do capital como modo estranhado de controle social.

Como salientamos acima, a expansividade do capital é sintoma da crise estrutural. Deste modo, crise e expansividade - e não estagnação - é o duo perverso da dinâmica capitalista. Assim, sob o "capitalismo das bolhas", o sistema do capital busca se reordenar "queimando" capital fictício, expondo as vísceras do Capital-Moloch que destrói irremediavelmente trabalho vivo.

A crise financeira global de 2008 está sendo deveras intensa e irá alterar, a médio prazo, de forma significativa, a dinâmica produtiva real. Embora seja fictício, o capital queimado é parte da realidade do sistema capitalista de produção de mercadorias - uma realidade de crise de valorização que é lembrada nos momentos de estoutro da bolha especulativa. O mercado financeiro escoava parte da massa de capital-dinheiro, alavancada mo mercado financeiro secundário (hedges e derivativos), massa de riqueza abstrata incapaz de ser valorizado na esfera produtiva por conta da crise estrutural de valorização.

Embora tenham sido abertas novas áreas de exploração e produção de valor, os novos campos de acumulação não conseguiam estar a altura das necessidades de valorização postos pelo novo quantum de capital-dinheiro acumulado nas últimas décadas de politicas neoliberais, que intensificou a exploração e acumulo de valor que se torna incapaz de realizar no âmbito produtivo. Enfim, a financeirização da riqueza é uma necessidade estrutural do capital nessa atual fase. È parte da vida orgânica da produção de mercadorias nas condições da crise estrutural.

A medida que a massa de riqueza abstrata cresce, torna-se difícil valoriza-la. Por isso, o estouro da bolha tende a significar (1) redimensiona a organização da produção, exigindo uma nova onda de exploração capaz de recompor bases da valorização para um capital-dinheiro sedento de mais-valor. Incapaz de ir além de seus limites estruturais, o capital "foge para a frente", acirrando, ampliando e intensificando suas contradições objetivas. A nova onda de exploração, vai significar mais acumulo de capital-dinheiro e incapacidade de realizar o valor na esfera da produção de mercadorias, exigindo, a reconstituição das formas fictícias de valorização (bolhas). É importante salientar que, neste crise de 2008, não se queimou todo o excesso de capital fictício. 
A nova onda da exploração da força de trabalho e espoliação do trabalho vivo que emerge com a crise tende a aprofundar o traço distintivo do capitalismo global como "capitalismo manipulatório" (Lukacs). Além disso, coloca elementos ampliados de barbárie social e a necessidade da regulação estatal no plano social, abrindo novos espaços de luta de classes no âmbito do poder estatal.

A década de 2010 será uma década de intensas lutas sociais, colocando em xeque, de forma irremediável, o "modelo neoliberal" que vicejou nas décadas de 1980 e 1990, embora não se possa dizer que haja alternativas sustentáveis para a dinâmica capitalista que consiga romper o primado irremediável do mercado. Pelo contrário, as contradições objetivas devem se agudizar, com destaque para a contradição entre a socialização objetiva da produção em escala planetária e a apropriação privada cada vez mais concentrada (a crise global deve concentrar mais ainda o capital, fortalecendo o oligopólio mundial).

Uma outra candente contradição é aquela entre o "recuo das barreiras naturais" - ou o avanço do desenvolvimento científico-tecnológico - que caracteriza o processo civilizatório do capital, e a constituição paulatina, de barreiras ao desenvolvimento humano-genérico; isto é, a agudização do que Lukács salientou como sendo o estranhamento social. Uma massa crescente da Humanidade encontra-se alienada dos progressos do trabalho social de homens e mulheres objetivados na ciência e na nova base técnica de cariz tecnológico.

Ao salientarmos que o primado do mercado deve prevalecer e tornar-se mais agudo na próxima década, queremos dizer que o Estado político, que intervém hoje para "salvar" os mercados financeiros e o sistema das economias capitalistas, deve canalizar, cada vez mais, o fundo público para os interesses dos mercados (algo que se verificou com clareza nas últimas décadas neoliberais). Na verdade, o Estado político intervém para colocar "regular" - e não abolir - a irracionalidade dos mercados financeiros, precarizando, deste modo, o fundo público e acirrando a crise fiscal estrutural do sistema.

Ora, Estado político e mercados são determinações reflexivas da mesma ordem sócio-metabólica do capital, que como um Moloch moderno devora a sociedade global. É provável que o capitalismo global, após o estresse da crise global que abala os mercados mundiais, irá conhecer, na próxima década, um novo patamar de expansão planetária, mas às custas de mais precarização do trabalho vivo e da força de trabalho e a dilapidação dos recursos naturais, embora sob um controle estrito do "cassino financeiro" (o que não impede que se constitua uma financeirização regulada, capaz de garantir investimentos na esfera financeira, como necessidade estrutural do capital-dinheiro sob as condições da crise estrutural da valorização produtiva do capital). Enfim, o Estado político do capital deve se fazer mais presente na economia - não para reconstituir um Welfare State, mas sim para administrar a ordem sistêmica.

Por isso, outro resultado da crise financeira global é politizar, mais ainda, a economia do capitalismo global. Na medida em que o Estado politica do capital socorre os mercados financeiros, injetando trilhões de dólares para salvar blocos de capital financeiro, alimenta o Capital-Moloch. Aumenta a dívida pública mundial, abrindo espaços de luta intensas na instância política dos Estados burgueses. A disputa pelo orçamento público deve se acirrar mais ainda. O Estado politico do capital "capturado" pelas demandas do mercado financeiro, deve agudizar sua crise de legitimidade. Nesse contexto, caso haja uma longa recessão global (o que só podemos saber em 2009), deve-se impulsionar movimentos sociais populares nos "elos mais fracos" do sistema mundial do capital. Nas condições de uma nova ofensiva do capital na produção deve-se agudizar a crise do sindicalismo integrado à gestão do capital, incapaz de lidar com as últimas ondas de reestruturação produtiva. 
A crise global pode aprofundar a lenta deterioração da hegemonia dos EUA no sistema mundial, embora não signifique a perda de centralidade política (e militar) do Império estadunidense no jogo de poder mundial. A China deve desacelerar um pouco seu crescimento econômico nos próximos anos, mas irá consolidar seu avanço para um capitalismo regulado politicamente, acirrando contradições internas por conta de candentes problemas sociais ligados a dinâmica da acumulação do capital. Enfim, a década de 2010 deve ser uma década de intensas lutas sociais ampliadas do conjunto da massa de homens e mulheres imersos na condição de proletariedade universal.

Esta crise global dá inicio, precocemente, à década de 2010, tornando claro que a crise estrutural do capital não é apenas uma crise econômica, mas como sim, a crise da Humanidade dilacerada pela lógica sistêmica do capital (isto é, crise ecológica e crise de sociabilidade). Embora, os governos burgueses tenham respostas pontuais e administrativas para o caos dos mercados financeiros, que esterilizou trilhos de dólares de capital fictício nos últimos meses, eles pouco podem para deter a nova onda de precarização social que pode atingir os paises capitalistas do centro e da periferia.

A verdadeira crise do capital não é crise econômica, mas sim uma crise social de ampla proporção, pois o capital não é - no sentido marxiano - uma categoria econômica, mas sim, antes de tudo, uma categoria social, um modo estranhado de controle do metabolismo social que dilacera o núcleo humano-genérico da Humanidade que emerge nos últimos séculos do processo civilizatório negado.

\section{A processualidade da crise financeira global de 2008}

O espectro da crise de 1929 ronda o capitalismo global. Desde agosto de 2007, vem se aprofundando a crise no sistema financeiro, desencadeada pelo estouro da bolha especulativa baseada em títulos imobiliários norte-americanos. A crise atingiu um estado agudo a partir de outubro de 2008, mas está longe do fim. Apesar das abrangentes medidas de socorro dos governos dos países centrais, que passaram por cima de dogmas sagrados do neoliberalismo, a crise já atinge a economia real e tudo indica que será prolongada e se alastrará pelo mundo, atingindo de forma desigual as regiões periféricas. O centro irradiador da crise é o próprio núcleo do sistema e não mais a periferia, como nos anos 1990. O estouro da bolha especulativa da Nasdaq, em 2000, foi o primeiro prenúncio de que a crise sistêmica tinha alcançado o centro do capitalismo.

Trilhões dólares de capital fictício na forma de ações e títulos foram, em pouco tempo, queimados. Subitamente os seus valores despencaram. A cadeia de títulos formada a partir dos títulos imobiliários norte-americanos, que abarcou as principais praças financeiras do globo, está desmoronando e seu desmoronamento leva a crise global de crédito, que está atingindo em cheio a produção e o emprego. Não obstante a injeção maciça de dinheiro nos mercados por parte dos bancos centrais dos países desenvolvidos, o "empoçamento" de liquidez continuará a deteriorar a situação dos bancos, dos fundos de investimentos e das companhias de seguros como também do setor produtivo. Além disso, as perdas de muitas grandes empresas, que especulam no mercado financeiro, foram pesadas.

O amplo socorro dos governos dos países desenvolvidos, que estatizaram parcialmente seus sistemas bancários e garantiram os depósitos bancários, deteve, pelo menos temporariamente, o colapso financeiro, mas a crise pode se arrastar como em 1929. É claro que a situação hoje é distinta. A incorporação da ex-URSS, da China, da Índia e de outras regiões periféricas, como novas fronteiras de acumulação de capital, alargando sobremaneira o mercado mundial, coloca novas questões. A crise põe em questão a 
solidez das moedas, em particular do dólar, que poderá ser crescentemente questionado como moeda chave da economia mundial, embora observemos uma fuga em direção aos títulos do tesouro dos EUA. Apesar do relativo deslocamento da valorização do capital fictício da produção de valor, as esferas produtiva e financeira continuam firmemente articuladas.

A crise vai aprofundar ainda mais o processo de centralização de capital, particularmente no setor financeiro. Processo já evidente nos EUA Observa-se também um clamor generalizado por mais regulamentação das finanças globalizadas. As instituições multilaterais, como o FMI e o Banco Mundial, tão ativas quando se trata de disciplinar a economia dos países pobres, impondo duras políticas recessivas, estão paralisadas, sem condições e disposição de tentar reverter o quadro. Abre-se espaço para a regulação dos mercados e para posturas alternativas ao neoliberalismo.

A crise financeira global de 2008, em parte, decorre de quase 30 anos de aplicação de políticas neoliberais, em especial da desregulamentação dos mercados financeiros e das economias nacionais. A ideologia neoliberal, que expressa sobretudo os interesses do grande capital oligopolizado, parece que entrou em fase terminal. Contudo, a crise não pode ser creditada apenas ao neoliberalismo. Ela resulta também de contradições mais profundas do capitalismo. Resulta sobretudo do predomínio do capital financeiro e de suas formas de valorização, em particular das bolhas especulativas. A própria hegemonia neoliberal só pode ser entendida no interior da proeminência do capital financeiro desde a década de 1980.

A crise de superprodução dos anos 1970 abriu uma fase de baixo e desigual crescimento econômico na economia mundial que se estendeu até 2003. A crise de superprodução, articulada a crise do sistema financeiro internacional estabelecido em Bretton Woods, criou as condições para o chamado padrão dólar-flexível, importante elemento para a reafirmação da hegemonia dos EUA e o predomínio do capital financeiro. O ritmo lento da acumulação no centro do sistema contribui para gerar um excedente de capital na forma dinheiro, inflando a esfera financeira, que se deslocou relativamente da produção. Quando o capital fictício se desloca muito das condições reais de valorização, mais cedo ou mais tarde, esse capital tem que ser desvalorizado para recompor as próprias condições de valorização.

O capitalismo reagiu à crise dos anos 1970 reestruturando-se. No centro, iniciou-se um processo de desmonte do Estado de Bem-estar Social, redirecionaram-se os gastos públicos para sustentar a valorização do capital financeiro, sobretudo por meio da ampliação da dívida pública. A reestruturação produtiva, que foi importante no enquadramento da classe trabalhadora, e a realocação regional de vários segmentos produtivos, que incorporou milhões de trabalhadores da Ásia e da Europa Oriental à economia mundial remunerados com salários diminutos, colocaram em cheque as conquistas do movimento operário nos países desenvolvidos. A realocação espacial de segmentos da indústria, em especial no Leste Asiático, induzida pela busca incessante de valorização do capital, contribuiu para abrir uma nova fronteira de acumulação, que ganharia peso crescente na economia mundial. Esse processo também estava determinado pelas transformações internas dos países da região e pelas suas políticas de desenvolvimento. O peso do crescimento acelerado do Leste Asiático, sobretudo da China, ficaria evidente a partir de 2003, quando a economia mundial retomaria um vigoroso crescimento. No entanto, vastas áreas da periferia, como a América Latina, viveram momentos de grande instabilidade e crise econômica e social. Outro elemento da reestruturação do capital foi a desregulamentação das finanças e das economias nacionais. 
Processos, que liderados pelos governos dos EUA e da Inglaterra, foram decisivos para a constituição do mercado financeiro global.

Como resultado desses processos observa-se a recomposição da taxa de lucro em queda desde o início da década de 1970, que voltou a crescer a partir de meados da década de 1980, com base no incremento da exploração da força de trabalho. No centro do sistema, com exceção dos EUA na segunda metade dos anos 1990, a taxa de investimento, como aponta Chesnais (1998, p.9-18), não acompanhou esse crescimento, o que significou fraco estimulo para o crescimento, dificuldade crônica de valorização do capital e, por conseguinte, continuo inchaço da esfera financeira. As causas da tendência ao lento crescimento estão no baixo nível de investimentos, na redução do consumo dos trabalhadores e na estagnação de vastas áreas da periferia. Esse desempenho não pode ser visto desconectado do que acontecia no Leste Asiático, em particular na China. Nessa região, observa-se forte aceleração da acumulação, o que levou a enorme expansão da capacidade produtiva no setor manufatureiro, que, somada aos elevados investimentos na chamada nova economia nos EUA nos anos 1990, gerou problemas de sobreacumulação em escala mundial, que estiveram na raiz das crises de 1997, na Ásia, e 2000, no estouro da bolha da Nasdaq. (Chesnais, 2006; Brenner, 2006).

O predomínio do capital financeiro resultado da reestruturação capitalista foi acompanhado de transformações na burguesia, que teria, segudo chesnais (2005), se tornado uma classe rentista e passado a apresentar um comportamento patrimonialista, impondo uma "forma radical do direito de propriedade". Submetendo as empresas e os assalariados à lógica de rentabilidade do capital financeiro. A majoração dos dividendos e juros exigida pelo capital portador de juros resultaria na redução dos lucros retidos para financiar os investimentos e levaria a rejeição de projetos que não assegurassem as taxas requeridas pelos acionistas.

A dominância do capital financeiro gerou uma dinâmica econômica instável e baseada em bolhas especulativas. A formação e o estouro de bolas especulativas têm caracterizado o padrão de acumulação do capitalismo global desde o finlda década de 1980 (Brenner, 2006). Entre 1990 e 2007, tanto os momentos de expansão quanto os de retração estiveram determinados por estouros de bolhas especulativas.

A instabilidade do novo padrão de acumulação predominantemente financeirizado começou a ficar evidente quando da crise nas bolsas de valores nos EUA em 1987 e logo depois na recessão 1990-1991. Para combater a recessão de 1990-1991 os governos dos países desenvolvidos, em particular o dos EUA, reduziram os juros e ampliaram o crédito. A saída para o capital financeiro, em um contexto de baixa remuneração no centro do sistema, foi dirigir-se em massa para a periferia, que passava por um processo de reestruturação de suas dívidas externas e de abertura de suas economias nacionais, comandada por governos que tinha abraçado o Consenso de Washington.

Esses capitais ávidos por valorizar-se, sustentaram sua valorização, em boa medida, especulando com ações, títulos, imóveis e moedas das economias periféricas, que apresentavam taxas de juros superiores as dos países desenvolvidos, decorrentes, muitas vezes, dos planos de estabilização econômica baseados em âncoras cambiais. Também obtiveram enormes ganhos nos processos de privatização das empresas estatais e na compra de empresa privadas. A insustentabilidae desses planos na América Latina e a valorização das moedas de vários países asiáticos, que tinham aberto suas economias nacionais e estavam acossados pela crescente concorrência chinesa e japonesa (depois da desvalorização do yen em 1995), abriram um período de forte instabilidade na periferia, cujo ápice foi a crise asiática em 1997. 
A economia mundial não entrou em colapso em virtude de outra bolha especulativa que se desenvolvia nos EUA com base na especulação com as ações das empresas de alta tecnologia na Nasdaq e pela continuidade do crescimento econômico dos EUA (com seus crescentes déficit externos), da China e da Índia. A bolha especulativa na Nasdaq contribuiu para que crise não atingisse com toda força o núcleo do sistema e para estancar a crise na Ásia. Os governos centrais e o FMI rapidamente, como tinham feito no caso do México, articularam pacotes de emergência para estancar a crise. Porém impuseram duras políticas de ajuste para os países da região.

A bolha nos EUA estourou em fins de 2000, pois a valorização fíctícia não conseguiu resistir por mais tempo "a atração gravitacional da queda dos lucros" nas empresas de alta tecnologia, que vinham caindo desde meados da década de 1990 em decorrência do setor apresentar excesso de capacidade produtiva, que também tinha sido um dos elementos importantes da crise asiática. (Brenner, 2006).

A crise financeira se espalhou rapidamente e as perdas se generalizaram. A retração da economia norte-americana afetou o conjunto da economia mundial. Contudo, cabe observar que as economias em desenvolvimento da Ásia sofreram relativamente pouco e passaram a acumular enormes volumes de reservas. A América Latina entrou em crise.

À época, muitos analistas de mercado e economistas esperavam uma crise de amplas proporções em 2000, mas o estouro da bolha apenas abriu um período de desaceleração do crescimento, que durou até 2003. A partir desse ano, a economia entrou em uma fase de intenso crescimento, comparável ao do período 1950-1973. O aprofundamento da crise foi evitado pela pronta ação do governo dos EUA e do FED e em virtude do crescente peso das economias asiáticas na economia mundial, em especial da China.

A ação do FED foi abrangente e rápida. Os juros foram reduzidos e o crédito ampliado. De especial importância foi a redução dos juros de longo prazo, decisiva para criar uma nova bolha especulativa sustentada em imóveis. O governo Bush também baixou um pacote fiscal, baseado na redução de impostos, e elevou os gastos militares em decorrência das guerras no Afeganistão e no Iraque. O governo dos EUA adotou uma política anticíclica tipicamente keynesiana (Brenner, 2006).

A valorização dos imóveis permitiu largo endividamento das famílias por meio de novos financiamentos e isso possibilitou o forte incremento do consumo, que passou a puxar o crescimento da economia. Enquanto o setor industrial permanecia mergulhado na crise, a economia norte-americana se recuperava com base na expansão do consumo, da construção civil, do setor de serviços, do comércio e do setor financeiro. Essa forma de recuperação se alimentava da febril especulação imobiliária, que acabaria envolvendo o sistema financeiro global. (Brenner, 2006).

A repercussão da retomada do crescimento dos EUA não tardou, ainda mais que esse crescimento foi acompanhado de déficits comerciais cada vez maiores, que chegaram a 6,2\% do PIB em 2006, beneficiando sobretudo os países asiáticos. Mas esse crescimento não estava concentrado em alguns países asiáticos como no período anterior, mas sim tinha se generalizado. Parte desse crescimento deveu-se aos efeitos do crescimento da economia chinesa no conjunto da economia mundial, em especial no que diz respeito ao consumo de commodities, cujos preços subiram sobretudo devido ao crescimento chinês e a especulação, que também atingiu intensamente as commodities. No capitalismo globalizado o processo de acumulação, que tem na China seu pólo dinâmico, e o processo de valorização financeiro-especulativa, centrada nos EUA, estão articulados.

Contudo, o centro do capitalismo global continua sendo a economia norteamericana, apesar dos seus crescentes desequilíbrios, particularmente nas contas externas. 
Os EUA só puderam aumentar sistematicamente seu déficit em transações correntes porque o resto do mundo, em especial os países asiáticos, está disposto a financiá-los. Fazem isso devido os seus próprios interesses de ampliar suas exportações, o que implica sustentar o excesso de consumo dos norte-americanos, e a falta de opção em manter suas reservas em outra forma que não em ativos em dólar, dado não existir ainda outra moeda de livre curso internacional e dado também o fato dólar não ser mais lastreado no ouro. Ao adotarem essa política, contribuem para manter suas moedas desvalorizadas e, de outro, estabilizam a economia norte-americana, permitindo a adoção por parte dos EUA de políticas expansionistas, que contribuem para impulsionar a economia norte-americana e, portanto, suas próprias exportações e produção Existe uma espécie de simbiose entre a as economias asiáticas e a norte-americana. (Belluzzo, 2005).

Os relativamente baixos preços das importações norte-americanas contribuem para impedir a elevação da inflação e, portanto, possibilitam a política de juros baixos e expansão do crédito e do gasto púbico. Fundamental para o crescimento econômico, sustentado, em grande parte, em cima de bolhas especulativas. Esse processo baseou-se em enorme volume de emissão de títulos imobiliários. Parte considerável constitui-se de títulos de solvência duvidosa. Para fugir do risco, os bancos e as instituições de crédito imobiliário norte-americanas securitizaram esses títulos. Espalharam-se pelo mundo todo ativos direta ou indiretamente contaminados pelos títulos hipotecários insolventes, o que coloca a possibilidade de colapso o sistema financeiro. Isto explica o pânico atual e a incapacidade das medidas adotadas até o momento em detê-lo. A crise só amainará quando o volume de capital desvalorizado for o bastante para recompor as condições de valorização.

Em 1929, a crise e a depressão que se seguiu destruíram o capital financeiro, que vinha se agigantando desde o final do século XIX, e contribuíram para a eclosão da II Guerra Mundial. Criaram também as condições para a retomada do processo de acumulação em novas bases no pós-guerra. Fundadas no capital produtivo, no Estado do Bem Estar social no centro do sistema e no desenvolvimentismo na periferia. A atual crise levará o capitalismo a reestrutura-se novamente. A continuidade da hegemonia norteamericana e do capital financeiro parece depender dos encaminhamentos dados a débâcle financeira e a essa nova reestruturação.

\section{Bibliografia}

ALVES,G. 1999. Trabalho e Mundialização do Capital: A Nova Degradação do Trabalho na Era da Globalização. Londrina:Editora Práxis.

2000. O Novo (e Precário) Mundo do Trabalho: Reestruturação produtiva e crise do sindicalismo. São Paulo: Boitempo Editorial.

2001. Dimensões da Globalização: O Capital e Suas Contradições. Londrina: Editora Práxis.

BELLUZZO, L. G. M. (2005) "O dólar e os desequilíbrios globais". In: Revista de Economia Política. São Paulo: V.25, n. 3, jul-set. (2007) "É capitalismo estúpido". In: Carta Capita, 22/08/2007, p.26-27.

BRENNER, R. (2006) "Novo boom ou nova bolha? A trajetória da economia norteamericana”. In: SADER, E. (org.) - Contragolpes. São Paulo: Boitempo. 
CHESNAIS, F.(1998) - 'Rumo a uma mudança total dos parâmetros econômicos mundiais dos enfrentamentos políticos e sociais". Outubro, São Paulo, nº 1, p. 7 - 32, maio.

(org.) (2005) - A finança mundializada. São Paulo: Boitempo.

CORSI, F. L.(2008) -“Capitalismo global; crise, bolhas especulativas e periferia”. In: Tumolo, P. S. e Batista, R. L. - Trabalho, economia e educação: perspectivas do capitalismo global. Londrina: Praxis/Massoni, 2008.

MEDEIROS, C. A (2006) - "A china como um duplo pólo na economia mundial e a recentralização da economia asiática”. In: Revista de Economia Política. São Paulo, v. 2, $\mathrm{n}^{\circ} 3$, julho-setembro de 2006.

\footnotetext{
' Professor doutor em Economia da Faculdade de Filosofia e Ciências da Universidade Estadual Paulista (UNESP)- Marilia (Brasil).

ii Professor livre-docente em sociologia do trabalho da Faculdade de Filosofia e Ciências da Universidade Estadual Paulista (UNESP)-Marilia (Brasil). E-mail: giovanni.alves@uol.com.br. Home-page: www.giovannialves.org
}

Artigo recebido em: 10/12/2008

Aprovado para publicação em: 17/01/2009 